\title{
Research on Rock Magnetic Study of the Early-Middle Permian Strata in the Keping Area of Tarim
}

\author{
Yanan Zhou, Xingfeng Yang, Siyuan Yang \\ Northwest University, Department of Geology, Xi'an, Shaanxi, 710069, China
}

Keywords: Tarim; Early-Middle Permian; rock magnetism; magnetic minerals; Kupukuz Full Group

\begin{abstract}
Determining the magnetic mineral characteristics of the Early-Middle Permian strata in the Tarim can provide a reference for its structural magnetic studies. In this paper, the systemic rock magnetic analysis of the Kubanku group basalt samples from the Early-Middle Permian in the Keping area was carried out by means of saturated isothermal remanence, magnetic susceptibility-temperature curve, hysteresis loop and day diagram. It indicates that the main magnetic bearing mineral of the Kupukuz full group basalt sample is magnetite; the magnetic mineral particle size is a mixture of single domain particles and multi-domain particles.
\end{abstract}

\section{Introduction}

The Tarim block is one of the three ancient land masses in mainland China, sandwiched between the Tianshan Mountains and the Kunlun Mountains and the Altun Mountains (eg, Huang Yuqing, 1960; Zhu Xia, 1983; Pan Yusheng, etc. 1990; Xiao Xuchang et al., 1991; Jia Chengzao et al., 1992). The Carboniferous-Permian period was considered to be a period of transition from the paleo-global tectonic movement mechanism to the new global tectonic movement mechanism. During this transition period, the interior of the Tali board experienced large-scale magmatic activity, which was characterized by a large amount of basalt erupted. The intrusion of acid tuff and large-scale basic rock wall groups constitutes another large igneous province after the Emeishan large igneous province in China (Fig.) (eg: Chen Hanlin et al., 2006; Yu et al., 2011; Yang Shufeng et al. , 2014). The tectonic evolution process of the Tarim Basin is a hotspot and frontier issue in the current scientific research.

The systematic study of rock magnetism is the basis for studies in structural magnetism, magnetic stratigraphy, and environmental magnetism (King et al., 1991). Identifying the types and combinations of magnetic minerals in rock samples can not only provide a theoretical basis for the separation of residual magnetic signals in indoor sample systems, but also help to deepen the understanding of the magnetization mechanism of rock samples (Huang Baochun et al., 1994). In addition, some of the magnetic parameters of rock may also reflect the information of the source and the difference of sedimentary environment (Jiang Yuehua et al., 2004). In the past, scholars at home and abroad have conducted structural magnetism studies on the Permian strata of the Tarim plate, but due to the lack of fine rock magnetic results, the understanding of residual magnetic signals has been restricted to some extent. Therefore, this paper conducts a detailed rock magnetic analysis of the basalt strata of the Kupu gluten group in the Shishichang section of the Keping area of Tarim, and uses the kT curve, hysteresis loop and Day map to identify the main magnetic minerals in the stratum. And the particle size of mineral particles, in order to provide rock magnetic basis for the study of tectonic evolution process in the Tarim Basin.

\section{Regional Geological Survey and Sampling of the Study Area}

Within the Tarim block, a large number of magmatic rocks formed by intraplate magma and dominated by basic rocks are developed. Based on the existing profile data, the basalt facies exposed in Keping area are the best preserved compared with other areas, and the profile is continuous and complete. Therefore, this paper selects the four stone field profile of Aksu City in 
Keping area for rock magnetism. The Lower-Middle Permian section of the Four Stones Plant in Aksu City is located in the Shishi Plant, about $12 \mathrm{~km}$ northwest of Shajingzi in Aksu City. The section passes through the Sishi Factory and is the continuation of the Lower Permian Conklin Formation in the Carboniferous. The Kupuku nourishing group and the Kaizhikeke Formation are visible on the section.

The Kupuku nourishing group is $430.3 \mathrm{~m}$ thick and can be divided into two subgroups. The lower subgroup is $270.0 \mathrm{~m}$ thick, and the lithology is dominated by variegated sandstones dominated by light gray and grayish white, with unequal thickness interbeds with fine conglomerate and calcareous tuffaceous sandstones, with argillaceous limestone, conglomerate and thin Coal seams, etc., the coal seam is difficult to see on the surface, the lower fossils are rare, and occasionally bivalves, sporopollen fossils are found on them. The upper subgroup is $160.3 \mathrm{~m}$ thick, with black basalt and dark green tuff sandwiched with pebbled sandstone, siltstone, mudstone, thin layer of gypsum and thin coal seam, containing Middle Permian Qixia sporopollen, bivalves, plants and gastropods. Wait. The isotope dating results of a large number of magmatic rocks indicate that the eruption time of the Kupukuz full magma sequence is 290 275 Ma (Yang et al., 2006; Zhang et al., 2010; Yu et al., 2011; Zhang Dayu et al., 2010). In addition, Chen Hanlin et al. (2006) identified the early Middle Permian metamorphisms (Whiphlella-Darwinula combination) and large plant fossils (Autuniaconferta-Pecopertis-Cordaites combination and Dichophyllumflabellifera combination) from the Kupukuz Manchu Formation sedimentary strata. Based on the comprehensive chronology and paleontological results, this paper tends to form the Kupukuz Manchu Formation in the Late Permian-Middle Permian. We collected more than 20 pieces of rock magnetic samples in the Kupukuz group basalt strata of the Shishichang section. Among them, the isothermal and triaxial experiments used standard columnar samples, and the k-T curves and hysteresis loops used powder samples.

\section{Rock Magnetic Results}

In this study, the saturation isothermal remanence experiment (IRM) and kT (magnetic susceptibility versus temperature curve) experiments and hysteresis loop experiments were selected, and the Day graph was drawn on this basis (Day et al., 1977). , clarified the type, combination and mineral particle size of the rock.

The Hopkinson effect in the kT curve means that the magnetic minerals will gradually increase in the heating process and reach the highest at the de-blocking temperature, and then gradually decrease until it reaches the Curie temperature point and drop to zero (Hopkinson, 1889). According to this effect, it can be seen from the kT curve in Fig. that the temperature rise curve of most samples shows a distinct Hopkinson peak around $400{ }^{\circ} \mathrm{C}$, and the temperature rise curve of the sample drops to zero at around $585^{\circ} \mathrm{C}$, that is, the Curie of rock magnetic minerals. The point is $585^{\circ} \mathrm{C}$, which is completely consistent with the physical properties of magnetite. This indicates that the main magnetic bearing minerals of this type of sample are mainly magnetite; from the IRM curve in Figure 4, the magnetization of the rock has reached saturation at $0.2 \mathrm{~T}$ field strength, indicating the magnetic loading contained in the sample. Minerals are mainly minerals with low coercivity.

According to the hysteresis loop shape standard proposed by Tauxe, the hysteresis loop shape of samples A0109 and A0207 (Fig. 4(a), (b)) is a typical "thin waistline" indicating magnetic mineral grains. The diameter should be a typical PSD, and the coercivity of the sample is lower, less than $20 \mathrm{mT}$, indicating that this may be caused by the inclusion of MD particles in the sample. As can be seen from the Day diagram of Figure 4(c), these samples with high Hcr / Hc values and low Mrs / Ms fall in the PSD region, indicating that the particle size of the magnetic mineral particles in the sample should be the result of mixing various particle sizes. .

In summary, the magnetic mineral type of the Kupukuz full group of basalt samples is magnetite, and the mineral particle size is a combination of interacting SD particles and a small amount of MD particles. 

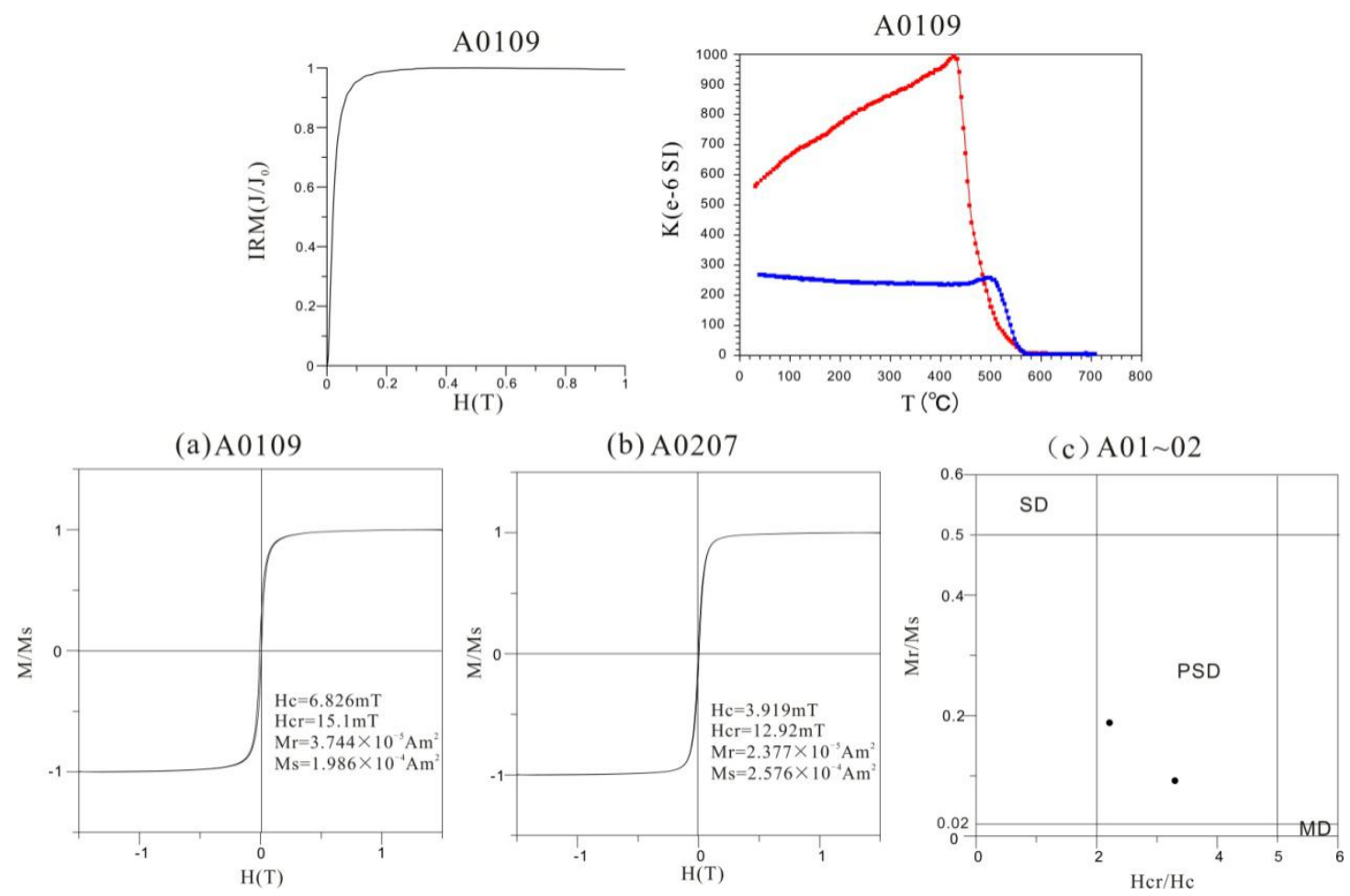

Fig.1 IRM curve of the representative sample of the Kupukuz formation, the magnetic susceptibility curve with temperature (K-T)

(The red line in the KT curve represents the temperature rise curve, the blue line represents the temperature drop curve) and the hysteresis loop of the representative sample of the first layer of basalt in the Kupkuz full group and the projection of its representative sample on the Day chart (Hc is the coercive force, Hcr is the remanence coercive force, $\mathrm{Mr}$ is the residual magnetization, and Ms is the saturation magnetization.

\section{Conclusion}

Based on the characteristics of isothermal remanent magnetism, thermomagnetic characteristics, hysteresis characteristics and demagnetization curve, the rock magnetic characteristics of the Kupukuman basalt in the Keping area of the Tarim Basin are recognized by two points:

(1) The rock magnetic results indicate that the main magnetic bearing mineral of the Kupukuz Manchu basalt sample of the Shishichang section is magnetite.

(2) The magnetic mineral particle size type in the Kupukuz full group basalt samples is a combination of SD particles and MD particles.

\section{References}

[1] Day R, Fuller M D, Schmidt V A. Hysteresis properties of titanomagnetites: grain size and composition dependence [J]. Phys. Earth Planet.Inter., 1977, 13:260 267.

[2] Hopkinson J. Magnetic and other physical properties of iron at a high temperature [J]. Philosophical Transactions of the Royal Society of London, 1889, A180:443.

[3] King J W, Channell J E T. Sedimentary magnetism, environmental magnestism and magnestostratigraphy[J] . Rev. Geophys. , 1991, 29:358-370.

[4] Tauxe L, Mullender T A T, Pick T. Potbelies, waspwaists, and superparamagnetism in magnetic hysteresis [J]. J. Geophys. Res., 1996, 101(B1):571—583.

[5] Yang S F, Li Z L, Chen H L, et al. 40Ar-39Ar dating of basalts from Tarim Basin, NW China and its implication to a Permian thermal tectonic event[J]. J Zhejiang Univ, 7(Supp II): 2006, 
170-174.

[6] Yu X, Yang S F, Chen H L, et al. Permian flood basalts from the Tarim Basin, Northwest China: SHRIMP zircon U-Pb dating and geochemical characteristics [J]. Gondwana Res, 2011, 20: 485-497.

[7] Zhang Y T, Liu J Q, Guo Z F. Permian basaltic rocks in the Tarim basin, NW China: Implications for plume-lithosphere interaction[J]. Gondwana Res, 2010, 18: 596-610

[8] Chen Hanlin, Yang Shufeng, Wang Qinghua, et al. Sedimentary responses of the Early-Middle Permian basaltic magmatism in the Tarim Plate[J]. Chinese Geology, 2006, 03:545—552.

[9] Huang Baochun, Tan Chengze. Separation Technology of Paleomagnetic Multimagnetic Components [J]. Progress in Geophysics, 1994,9(1):125-134.

[10] Huang Yuqing. Basic contours of China's tectonic structures [J]. Chinese Journal of Geology, 1977, 51(2): 117-135

[11] Jia Chengzao. Tectonic Evolution of Tali Wood Blocks [M]. Nanjing University Press, 1992, 22-29

[12] Jiang Yuehua, Yin Hongfu, Wang Runhua. Theories, methods and research progress of environmental magnetism [J]. , 2004, 25 (3): 357-362.

[13] Pan Yusheng. Tectonic Characteristics and Evolution of the West Kunlun Mountains [J]. Chinese Journal of Geology, 1990, 3:224-232

[14] Xiao Xuchang, Tang Yaoqing, Li Jinxi et al. Tectonic evolution of the southern margin of the Guzhongya complex giant suture zone [M]. Beijing: Beijing Science and Technology Press, 1991:1-29

[15] Yang Shufeng, Chen Hanlin, Li Zilong et al. The Early Permian Large Igneous Rock Province of Tarim Basin [J]. Chinese Science: Earth Science, 2014, 02: 187-199

[16] YANG Shufeng, LI Zilong, CHEN Hanlin et al. Discovery of the Permian quartz syenite porphyry rock wall in Tarim Basin and its tectonic significance [J]. Acta Petrologica Sinica, 2006, 05: 1405-1412

[17] Zhang Dayu, Zhou Taofa, Yuan Feng et al. The zircon LA-ICP-MS chronology and Hf isotope characteristics of the Kupukuzmann basalt in the Keping area, Tarim Basin, and its significance [J]. Acta Petrologica Sinica, 2010, 26: 963-974

[18] Zhu Xia, Chen Huanjiang, Sun Yucai et al. Mesozoic and Cenozoic tectonic and petroleum-bearing basins in China [J]. Chinese Journal of Geology. 1983, 3, 235-242. 